\title{
Chapter 11 \\ Conclusions: Perspectives and Puzzles in Researching Politics of (Dis)Integration
}

\author{
Violetta Zentai
}

Much has been written in academia about integration following migration to and within Europe in the post-WW II era. Integration has served as a central term in political, policy and scholarly debates to denote principles, discourses, interventions and social practices which ensure sustained interactions and cooperation across different groups or parts of society, including those who were born within and outside of particular, typically state, borders. The ideal of integration has mastered both the feared and the cherished aspects of social difference. Disintegration, in turn, has been posited as a concept referring to processes that neglect, diminish, dilute or deliberately deconstruct what liberal political systems have promoted through the idea of integration. (Dis)integration is investigated in this volume to examine the complex interactions and controversies of the twin processes of integration and disintegration by which societies and policies respond to people moving across (nation-state) borders and contribute to redrawing the social landscapes where they arrive. A European perspective is extended to other migrant destinations in the global North, more precisely to Israel and Canada, in order to offer insights into diverse domestic social and political practices as well as cross-national debates on the politics of human mobility.

The authors in this volume have originally contemplated to explore the politics of integration by engaging in multi-layered investigations into how migrants and refugees are defined, placed or moved by policies, institutions, and administrative protocols, yet deliberately, tacitly or inadvertently affecting institutions and relations in society at large. As highlighted in the introduction, the contributing authors have explored a whole continuum of practices producing integration and disintegration, often simultaneously or interlaced. The exchanges, cross-readings, and horizontal conversations across the authors' collective have helped the editors acknowledge that the nuanced attention to the processes of integration and

\footnotetext{
V. Zentai $(\bowtie)$

Central European University, Budapest, Hungary

e-mail: zentaiv@ceu.edu
} 
disintegration mechanisms can be best captured by the master concept of politics of (dis)integration. This concept, at first sight, embodies a tension, if not a contradiction: it implies that something systemic is coming together through changes that detach, distance or deconstruct what should or could be parts of a whole. The notion of politics refers to a plethora of actors who participate in dynamic acts of integration and disintegration, the outcomes of which are partly fluid and ambiguous, but in other cases controversial and harsh. The authors of this volume are scholars of migration accompanied by others who study Roma and other minorities. The scholarly endeavours behind the chapters have dwelt on recent or contemporary transformations in cognisance of wider and longer-term changes in European political and policy scenes, juxtaposed with Canadian and Israeli contexts of distinctive immigration and integration traditions.

In this concluding chapter, I reflect on some of the coalescing and occasionally diverging experiences and arguments that the authors of the volume have presented. This will be embedded in a review of key messages that the volume as a whole articulates regarding the conceptual, political and policy formations that tailor relations between people on the move and other members of society amidst weakening mechanisms for protecting human dignity, rights and equal citizenship in Europe and beyond.

\subsection{What Is Changing in Europe and Beyond?}

In the introduction to this volume Collyer, Hinger and Schweitzer propose that a European integration regime has been functioning for 50 years on shifting conceptual foundations but within a wider liberal consensus which has now become challenged. The regime on the wane emerged in post-WW II (Western) Europe in response to the arrival of guest workers from Southern Europe and later from the former colonies joining with the post-war economies. At that time, globalising economic relations attracted new labour migrants from all over the world to Europe from the 1980s (Favell 2014). Later, the internal borders in Europe got opened to the newly admitted member-states to the European Union (EU) in the 2000s. The enlarged EU generated hopes for managing migration practices by reducing internal boundaries and providing safe protection of its external borders. This migration regime, split between immigration and integration, is promoted by an 'embedded liberalism' favouring the interests of national economies (Rass and Wolff 2018, p. 29). The EU has retained major responsibility for security and border control, the least progressive aspect of immigration management (Favell 2014). The European scope of action, freed from nation-state confinement, has been left with a policy task largely distanced from the goals of social integration and the expansion of citizenship rights. Other sharper voices in the literature, inspired by Mezzadra and Nielson (2013), emphasise how objectives and imaginaries of immigration regimes have moved to dominate the concept of integration in Europe by bringing the state's 
border onto the state's territory and undermining integration policies way beyond the explicit targets of these policies.

The current volume encourages an understanding that migration is always conceived and managed in a wider complexity of visions, ideologies and policy paradigms aiming to respond to various differences, belongings and disparities in society. Therefore, it is important to note that the enduring integration regime in Europe has been underscored by the acknowledgment that the liberal order cannot solve all structural inequalities and smooth out all tensions of diversity understood beyond migration affairs. The recognition of historically accumulated disadvantages, the formation of legal and institutional safeguards against discrimination and further steps to ensure power-sharing between the disadvantaged and the privileged were strengthened across Europe in the 1980s and the 1990s (Shaw 2005). The advancement of the concept of multiculturalism enriched and partly rethought the human rights paradigm by advocating the recognition of collective identities and belonging, in particular along ethnicity, religion and language within nation-statebound societies. However, not even the heyday of multiculturalism eliminated certain hierarchies among groups in society that integration concepts tacitly or deliberately accepted.

The chapters of the volume have intensively commented on how the European regimes of 'migrant integration' started to change markedly from the mid-1990s. In view of the milestones in this process, contributing authors have referred to the postCold War start of the massive migration of Russian Jews to Israel in 1989-2000 which further hierarchised the citizenship regime of the country (Desille), the EU Roma integration strategic framework announced in 2011 by marking the Roma as the most vulnerable minority in Europe (Magazzini), the official announcement of a deliberately hostile environment for undocumented migrants in the UK in 2013 (Schweitzer), a 'refugee crisis' in 2015 involving a number of European polities (Cantat) and the passing of a new Integration Law in Germany in 2016 to define which refugees are (not) 'likely to stay' in the country (Hinger). Most of the scholarly voices in the volume resonate with interpretations that reveal a gradual shift to principles and goals of tighter population control, labour-force-driven social engineering and selective inclusion in the core through exclusions on the margins of society. These approaches had not been completely alien from European policy practices under the former integration regimes yet did not coalesce into a dominant scheme.

The broader literature also highlights paramount inequities in the European migration system and shrinking opportunities for inclusion for marked groups of migrants. The free movement of European citizens is accompanied by the tightening control of mobility from outside the European borders. The demands of labour markets are openly promoted, together with the noble goal of circulation of human capital and the belief in the entrepreneurial spirit of migration. However, belief in cooperation and solidarity between people of different or multiple group belongings and of varying mobility and placement conditions is diminishing (Favell 2014; Scholten and van Breugel 2018). Increasingly resistant or hostile attitudes have developed toward specific recipients in welfare provisions. Among these 'groups of 
suspicion', immigrants usually stand out (Banting and Kymlicka 2015; Lafleur and Mescoli 2018). Political statements demonstrating tight (or, at least, tightening) control still endorse a political economy which perpetuates the flow of foreign-born labour supply, wherever needed. Within this duality - one might even call it hypocrisy - deep European racist convictions and everyday routines of racialising exclusion also surface. Not restricted to newly arriving migrants, this often concerns populations of colonial origin and, most recently, the Roma, the stigmatised subjects of East-West migration within Europe. In recent extremist imagination and discourses, the ideological nexus of 'non-European'-ness increasingly conjoins the figures of 'Roma' with 'migrant', with 'Muslim', with 'terrorist', with 'criminal', with racialised Blackness (Yildiz and De Genova 2017). Even in less-antagonised political contexts, a negative integration spiral is often observed: social groups move away from each other even if mixed identities and increasing diversity within the immigrant groups, particularly in larger cities, soften the boundaries between majority and minority groups in society (Crul 2016).

Parallel to capturing the limiting and disconcerting transformation, the portrayal offered in this volume of contemporary European, Canadian and Israeli integration practices should also be seen within the state of the art in wider social justice struggles. More precisely, I propose to evoke the visions and platforms against racial/ ethnic exclusion and marginalisation in recent histories of European equality thinking. Group differences enacted along ethnic, racial and religious lines, including the position of migrants and the marginalised Roma, have been elevated to a protected ground in European politics and policy making by the EU's 'Race Directive' of 2000. Nonetheless, the politics of recognition of these groups and their conditions has always been more contentious than that of women, sexual minorities or people with disabilities, just to name few other protected grounds. Furthermore, socioeconomic (class) distinction has not become subject to transformative equality thinking in Europe, except in some Nordic countries, even if enduring poverty has been seen as violating human dignity. Notwithstanding, the European political and policy infrastructure for anti-discrimination, likewise the Canadian one, is perhaps more significant and transformative in its potential and partial effects, than assessed in this volume. This infrastructure has become constitutive of the wider European integration landscape in the last five decades, appearing the most prosperous in the 1990s and early 2000s (O'Cinneide 2013). Since then, it has become contested, or even weakened, due to mutating consequences of global capitalism, competing states within the enlarging Europe, inward looking welfare regimes, and populist electoral politics, to name some of the forces behind debasing the norms of human rights and equal citizenship practices. The volume has presented a compelling call for critical inquiries to relate more systematically the agendas of migration research with a comparative historical account of various European social justice struggles and tangible policy changes over the last five decades. 


\section{2 (Dis)Integration Politics and Policies}

The chapters in this volume have uncovered considerable variation in contemporary integration governance across localities and their recent histories. The authors believe in that the multi-scalar configurations of integration and disintegration practices can be examined through the interfaces and linkages between international, national and sub-national actors and domains. Cities with diverse populations linked to global economic and cultural exchanges and nation-state power structures are examined as multiscalar place-making configurations resonating with important recent trends in migration research (Çağlar and Schiller 2018). With due respect to the risk of methodological nationalism, the authors have also put the nation-state policy machinery under their magnifying glass in cognisance of its power, institutions and resources in shaping politics of (dis)integration. It is acknowledged that civil society actors and citizens also become constitutive of (dis)integration processes through their solidarity actions with and for migrants on the one hand, and xenophobic mobilization on the other. As Collyer et al. proposed in the introduction of the book, in the contact zones of authorities, migrants and host society and in various policy domains, contradictory processes embracing exclusionary and inclusionary drives and instances contribute to co-producing (dis)integration effects in society.

The individual chapters have shed light on different balances and tipping points between scales of action, frictions between politics and policy practices, and operations of policy or social sub-systems. For example, the chapters have revealed how immigration policies and integration measures may embrace saliently different paradigms, like in Malta with a more lenient former and more restrictive latter system. The recent refugee legislation in Germany constrains integration yet allows laxer border control. Other contributions have uncovered that national-level policy framings get contested or bent by sub-national actors such as some German cities and street-level bureaucrats in the UK. By the example of the Spanish and Italian Roma inclusion strategies, it has also been explained that the wide-spread policy jargon of social inclusion enables both difference and equality-based interventions and can usher in disintegrating moves and outcomes. Disjointed principles and practices are pursued and assembled together in the UK social services to help preventing 'illegal' immigration yet to respect the ethics of service provision, and in the Canadian regulatory regime concerning temporary migrant status.

In addition to portraying and explaining complexities, and transient or enduring properties or modalities of (dis)integration, the chapters together have contributed to sharpening knowledge on three essential components of (dis)integration practices: framing the organising principles of policy (non-)interventions, categorisation and hierarchisation of people, and everyday acts of exclusion and inclusion. 


\subsubsection{Framing}

Political and policy frames built and promoted by state or civil society actors targeting public issues encompass a problem statement, name the problem-holders, articulate a need for interventions or change and outline the direction of the latter. All this is glued together in a meaningful reasoning. The volume has mapped these frames and frame-making acts as domains of fight, change and contestation, rather than as sheer state machinery to legitimise and perpetuate population control.

Maintaining the foundations of the nation is an old but still paramount rationale for domestic policy regimes' interest in integration measures. Hinger, in her chapter, has revealed that the Integration Law of 2016 in Germany envisions the maintenance of a peaceful, liberal and communal society and, to this end, public policies will regulate the privileges and duties of asylum-seekers. In contrast, municipalities often consider the asylum-seekers as potential resources in a heterogeneous urban society. Magazzini has argued that the National Roma Integration Strategies - compulsory policy tools for multi-year actions in the EU member-states - in fact articulate what constitutes the idea of being 'national'. Of the two Roma integration strategies closely observed, the Spanish one defines the regular citizens' living conditions and expects the Roma to assimilate to them. The Italian strategy identifies separated social groups, the relations of which it intends to mediate. In Israel, contemporary immigration is supported to enable general socio-economic development, to balance out-migration, to enrich cultural diversity and also to provide new channels of public funds for municipalities, as Desille has argued. Thus, immigrants boost the resources of the host society and compensate for certain shortages that it may face. The well-being and sustainability of the nation is again a prime objective.

In other cases, the framing of integration actions is conceptualised around the in-betweenness of the refugees and other migrants. The study on Malta by Nimführ et al. has uncovered how transience and permanent temporariness are purposefully produced and institutionalised, thus showing an interesting analogy with the Polish state's perception of the returning migrants, which Karolak discussed in his chapter. Temporariness seems to justify minimum interventions and leaves in limbo the status, potential citizenship and recognition of those considered as temporary. In contrast, the framing of the status of temporary migrants in Canada and the UK by perpetuating the language of temporariness does not seem to strongly shape or limit the depth and intensity of integration effort in these contexts, as Samuk's chapter has shown. This might indicate that, in current political contexts, strategic framing, i.e. articulating less 'progressive' vocabulary, may tame political and popular resistance to hosting migrants and enable more supportive actual integration measures.

The volume has eloquently revealed that forms of disintegration are also produced by non-action or willful and justified negligence by state or other responsible authorities. As Cantat has shown in her chapter, the current Hungarian refugee management system turns its back on the needs of asylum-seekers. The dominant immigration policy frame aggrandises the role of the Hungarian state to defend the Schengen borders. The refugees' needs and humanity are erased from the policy 
vision. Karolak has examined how the Polish state has had a lukewarm reaction to the problem of large numbers of returning migrants in a belief in their increased skills and employability. The deployed integration frame overvalues the assets of the returning migrants and turns a blind eye to the context of the growing precarisation of work. More closely, some kind of involvement in the labour market, regardless of its quality and stability, is viewed as integration by default. Further, as Karolak suggests, this approach to return migrants valorise a flexible, docile and politically abstinent global workforce and distracts the attention from the vulnerable, typically low-skilled migrant workers. Sahraoui has found that it is the dominant frame of direct discrimination and the individual complaint principle that are posited against the racialising employer practices concerning migrant care workers in larger European cities. In fact, structural discriminations are produced on a massive scale by the intersections of migration, employment and care regimes. The preferred anti-discrimination principle with its restricted attention to equal treatment and individual scope neglects the duty to protect the vulnerable and to prevent institutional discrimination. This restrictive policy lens bleaches the existing European equality norms which have moved beyond the sheer prohibition of discrimination and individual legal actions.

Several chapters in this book have touched upon the hidden references to or more tangible imaginaries of racial hierarchy in European societies, one of the most stubborn and controversial forces of disintegration. Racial oppression has been explained as a wicked form of inequality and exclusion in the norms and vocabulary of liberal democratic politics. In spite of the major international human rights treaty mechanisms and the hard law provision in the European Union (Race Directive), racialised ethnic 'othering' is still part of social imagination, politics and social relations in Europe. Racist discrimination can result from policies and practices, which might or might not be imbued with explicit racist ideology, as Sahraoui's chapter has discussed. Institutional practices effectively transform the experience of individual prejudice into forms of institutional racism. Against these institutional practices, standard liberal anti-discrimination frames appear as feeble and unsubstantial: they allow integrating various migrants in the labour market of larger European cities at the cost of regular maltreatment and abuse in which racial hierarchising can be captured.

\subsubsection{Categorisation and Hierarchisation}

Contemporary migration governance systems enact hierarchical integration opportunities for various groups of people on the move. A closer look shows that earlier state interventions had also been prone to use this practice. A wide array of policy analyses portrays the fact that states tend to hierarchise people to ensure control and rationalise divisible and indivisible resources (Mügge and Van der Haar 2016; Yanow et al. 2016). Categories are used to separate people and to rank their worth, 
their needs and the respect which they can be given, in order to justify differential degrees of deservingness. Inclusion-driven civic actors may also rely on categories for building solidarity, support and empowerment, but their intention is rarely to solidify social hierarchies. Hierarchies of people in European migration processes frequently resonate with a colonial imagination but without colonial powers. As several authors in this volume (Hinger, Samuk and Schweitzer) have argued, the categories that immigration regulations define set the (dis)integration paths that are available to migrants.

The divide between European and non-European migrants saliently structures public discourses and affairs in Europe and Israel but in a less obvious way in Canada as well. Desille's chapter has described the situation in which immigrants gain the attention of policy-makers when their economic performance is positive and when they fall into the category of vulnerability. This polarised practice is constructed by the interplay of Israeli nation-building, migration governance and integration policy. At the beginning, the line was drawn between Jewish immigrants of European and those of other origin. Today, the country of origin still plays a decisive role but has become enmeshed in a neoliberal discourse around un/deservingness based on perceived economic utility and the ability to actively participate in society. The 'Russians' are idealised as 'active, participatory and productive individuals', whereas groups from the Global South are accepted due to their potential vulnerability. This still strongly racialised distinction is translated into a dual (dis)integration regime: as Desille has shown, the resourceful ones are granted individual freedom and choices while the vulnerable ones are limited in their freedom and choices. The property of resourcefulness measured by a degree of fit to actual labour market needs is further differentiated by the skill capacities of the migrants. This neatly resonates with Samuk's finding that migrant workers categorised as lowskilled might very well have high(er) skills but refrain from claiming them in order to fit the host countries' labour market and/or visa regimes.

The most drastic practice of labelling people emerged in the recent European 'refugee crisis' in 2015. Some immigration regimes, with the disconcerting lead of the government of Hungary, disqualified all border-crossing refugees as 'illegal migrants'. This radical message was endorsed by the treatment of these refugees at the entry point to the country and at the point of their departure for their continued journey. Cantat warns in her chapter that migrants become illegal when legal provisions define certain forms of mobility as illegal. By promulgating the notion of illegality, the respective government normalises its indifference to suffering and its denial of solidarity in the name of the security of Hungarian society. This disqualifies any liaison between migrants and members of the host society, other than feelings of fear or suspicion. Although Germany emerged as the most inclusive and welcoming society in the milestone year of 2015 in European refugee politics, its 2016 law on integration introduced unambiguously restrictive measures. More closely, as Hinger has revealed, it defines a legal division between genuine and bogus asylum-seekers by assigning strong or weak 'likelihood of staying' and rendering their treatment and access to services accordingly. The significance of the distinction based on the notion 'likely (or not) to stay' is powerfully illustrated by 
the Bavarian 'special camps' for refugees who are 'not likely to stay'. The two cases illuminate that categorisation often becomes not only the effect, but part and parcel of the fundamental principles respected or denied in the dominant integration frames.

All these examples reveal that the categories that underlie integration policies are imbued with powerful classifications by simplifying complex narratives and biographies of human lives with the purpose of creating and endorsing order and hierarchy. These classifications reflect and endorse bureaucratic operations which always look indispensable, consequential, and neutral, thus detached from political controversies and struggles. The actual categories, such as 'refugees', migrants', 'illegal', 'legal', 'temporary', etc. function as empty vessels into which human beings can be placed by inducing a one-dimensional status embracing a specific moment in time and crafting the individual as being ahistorical and neutral in relationship to state authority (Sajjad 2018).

\subsubsection{Everyday Acts of (Dis)Integration}

State and market forces and their cooperation are seen as the most powerful actors to influence the conditions of integration and disintegration practices. This volume offers a number of important observations to refine this argument. Even in the most favourable institutional and framing constellations, in which state administration is mandated to care about equal access to citizenship, bureaucratic procedures often differ from the official policy ideals and frames. In reverse, as already mentioned, bureaucratic practices can, to some extent, resist restrictive paradigms enforced from above. The ways in which bureaucracies operate are embedded within broader cultural patterns of conduct and sociality (Rozakou 2017). This implies that bureaucracies could perform above and below the quality of their protocols and could be either devoted or reluctant supporters of equal citizenship ideals. In some cases, state authorities enact irregularity and disorder when organising their integration services. In other cases, routinised practices of security and control override any other principles of public service. In the contemporary political climate prone to sorting out un-welcome immigrants, one can expect bureaucracies, service providers and local authorities resonating with the expectation to perform restricted services to those who are marked as 'undeserving'. However, this is not always the case.

Several chapters in this volume have explored the behaviour and everyday practices of state at the nodal points of social-service provision (e.g. borders and cities). They have revealed how particular sites operate where the exclusionary logic of immigration law intersects with the different inclusionary practices of public service provision, including health care, education and social assistance in the UK, and services for newly arrived immigrants to help in their integration offered by the municipalities in Malta and Israel. Where the major divide is drawn between regular and irregular migrants, in order to effectively constrain the latters' access to various rights and services, the spirit of immigration law penetrates ever more spheres of 
everyday life and social interaction, as highlighted in the chapters by Schweitzer, Nimführ et al. and Desille. Consequently, control and surveillance are not only intensified but also gradually extended from the external boundaries to the interior of the state and society, as Mezzadra and Neilson (2013) indicate. This impacts fundamentally on how street-level bureaucrats handle irregularities in their daily encounters with service-users. They generate institutional innovations to maintain a firewall for the regular operation of public administration and to comply with the task of criminalising interaction with unlawful citizens, as Schweitzer notes in his chapter. This complicity, although incorporating some resilience, appears to disintegrate the classical ethos of social services and public administration.

The role of state authorities is also complex and contradictory in Israel and Malta. In the former, they have to develop two different modalities of operation: one for the resourceful migrants deemed to be productive and of high utility, another one for the discounted ones limited in their freedom and closely managed in their integration. In Malta, as opposed to several other countries in Europe, the authorities, in their first encounters with migrants, are mobilised by the norms of rescuing at sea. The authorities then treat migrants as transients and sojourners who only deserve to stay in inaccessible open centres equipped with temporary arrangements. By linking the modalities of framing, the hierarchical clustering of migrants and the everyday operation of state institutions, the chapters by Desille, Nimführ et al., and Samuk have all revealed that transience is not the property of the migrants: it is produced by the integrating state and its institutions.

It is worth acknowledging a particular tension in the political and conceptual views of the authors regarding the sub-national and local actors of state authorities. It is argued that, at the sub-national and local levels, the practicality of inclusion often reconfigures or neutralises the ethno-nationalist rhetoric and thus enables local actors be rid of the evils of exclusion or instrumental inclusion, as Magazzini discussed. An explicit clash between central and local policy-makers was captured by Hinger when discussing recent integration policy trends in Germany. She shows that local actors are still prepared to consider asylum-seekers - regardless of their status - as having rights to equal access to the welfare system and social institutions. Quite the opposite potential for local acts of integration is stressed by other authors. Nation-states often rely on local governments to struggle with the messy and costly details of servicing and policing the expanding non-citizen populations - Desille cites Varsanyi (2008) in her chapter. Other authors in the book also refer to migration scholars such as Glick Schiller and Çağlar (2011) who highlight that immigrants are seen as potential members of the 'creative class' acting as neoliberal agents of urban restructuring. In sum, the local domains of social interaction are more open and fluid than the national ones but often at the expense of further hierarchisation and selective support. The volume stresses that local policy-making appears more willing to consider different forms of migration as part of regular urban life in which inclusion is based on dynamic reactions to changes, rather than on restrictive formations of life conditions for migrants in the belief that authorities protect the majority. 
In other contexts, everyday acts of negligence or destitution towards refugees and asylum-seekers are produced behind hyper-visible spectacles of scrutiny and control at the country borders. These acts contribute, as Cantat has indicated, to the 'un-weaving of the social, economic and political ties' which migrants and refugees may build in society. It is proposed that border spectacles stage dramatic scenes of enforcement and demonstrate a state's ability to enforce the law, punish those who break it and exclude those deemed as illegitimate. These acts set the moral and ethical limits of the political community. Parallel to this, state-sponsored and complicit media discourses stigmatising migration have far-reaching disintegration effects in society writ large. Notwithstanding, this negligence also provokes everyday acts of solidarity which complicate the dynamics of producing and reducing integration. Authorities try to delegitimise and, most recently, to vilify the refugee solidarity actions of the host society and thus prevent the emergence of links with a national public, as Cantat has shown.

Another salient political economy configuration is that migrants accept jobs that are not taken by ordinary citizens in exchange for some degree of welcome. A regular form of unambiguous exclusion of migrant workers from within and outside Europe is to employ them in completely unregulated and separated time-space constellations. As a recently completed ethnography uncovers, the low skilled nightshift workers in global cities of Europe are at the mercy of their employers, who are rarely subject to labour inspections. These workers not only suffer from a lack of labour protection, but they are also barely able to develop any social and human ties, let alone seek political support outside their workplace. They not only have limited rights compared to ordinary citizens or highly skilled migrant workers, but they live outside the social spaces populated by regular citizens. They have never been integrated and nothing they do conveys the hope that they ever will be. Non-action for integration is normalised by the invisibility of these patterns of separated human lives and punctuated spaces between migrant and main society (MacQuarie 2018).

By lacing together observations on framing strategies, hierarchical categorisation and everyday acts of organisations and administration, the volume reveals that, with few exceptions, European nation-states (as well as Israel and Canada) are not withdrawing fully and noisily from the ideals of social integration or inclusion. However, many of them circumvent or undermine the integration of certain individuals or groups who are identified as undeserving, resourceless or illegal. As Collyer et al. have argued in their introduction, the increasing exclusion of irregular residents from public welfare affects not only the excluded, but also the institutions providing such services and ultimately societal relations more broadly. Equally importantly, the norms, pronounced frames and practices of integration policies become constitutive of a broader social imagination which renders particular experiences acceptable, disturbing or unacceptable. Normalising racial hierarchies, nonaction amidst perceived disparities and destitution and getting rid of the duty to protect, are all making their way in public affairs and discourses in contemporary Europe and Israel, whereas they are still resisted or neutralised in Canada. 


\subsection{Conceptual and Methodological Puzzles}

The volume also deserves acknowledgement for experimenting on three major conceptual and methodological puzzles. First, it has ventured to translate the concept of (dis)integration into an analytical device by teasing out the relations between migration and other societal affairs. Second, it has acted upon the critique of methodological nationalism yet continues to view the nation-state as a centre of politics and operational mechanisms that shape integration and disintegration debates, practices, and regimes. Third, it has instigated discussions on separating normative and critical positions seen to differentiate policy actions and reflexive social research.

The scholars contributing to this volume respect scholarly traditions that delve into politics of integration as a complex phenomenon combining discursive, administrative and institutional acts across scales that are not only given but shaped by these acts. They all share a conviction that integration and disintegration practices should be examined through relational approaches: even if a power group, typically a social majority or the 'mainstream', is devising paths for those who want to be part of particular social, economic and political spaces, the institutions and relations of the power group do not remain unaffected. Moreover, the majority or the mainstream is not necessarily composed within the structures of the nation-state.

The analytical frames applied in this book resonate with recent noteworthy proposals to pursue complex integration studies. Garcés-Mascareñas and Penninx (2016) offer a composite analytical scheme and holistic tool for comparative studies on integration policies. Beyond disaggregating different dimensions, social parties (migrants and the mainstream) and levels of analysis, it is proposed to dwell on policy frames, concrete measures and the horizontal and vertical processes in different policy domains, including those that specifically target migrants and those regulating broader societal institutions. Rass and Wolff (2018) have also drawn up a complex analytical frame to examine migration governance which has obvious overlaps with integration research. Their multi-layered scheme takes further steps to investigate regime formations without searching pre-analytical nation-state-framed domestic regimes. They sort out specific analytical tasks in relation to all constituting factors of a regime captured on three layers. The key tenets that the authors in this volume hold also correspond with the core arguments of the introduction to another recent and inspiring thematic journal issue. Hamann and Yurdakul (2018) suggest that traditional integration research viewed migration as a peripheral phenomenon on the margins of society, whereas contemporary critical inquiries conceive migration as a constituting force within societies. This shift enables scholars to look at society as 'inevitably and irrevocably shaped by migration' (ibid. p. 111).

One of the biggest challenges for the researchers in this volume has been to open up the box of wider societal structures beyond migration management and integration. The chapters offer rich insights into streams of collective imagination, governance practices and social-service institutions beyond migration management that all contribute to shaping (dis)integration acts. This richness does not eliminate the methodological puzzle of identifying the most relevant societal interactions that 
reveal how integration regimes are embraced and conditioned by broader structures and movements in society. It is fair to argue that the volume as a whole portrays a wide set of the mutations and the controversies of (dis)integration formations which is not yet a systemic account yet more than a colourful picture to which individual chapters offer context specific experiences and enunciations. The volume also presents a compelling invitation to investigate how politics of migrant (dis)integration generates effects beyond its scope, and as recent trends show, even game-changers in broader citizenship relations.

The chapters have all offered important insights into how politics of (dis)integration are shaped by a variety of actors who engage in migration and integration affairs, with their intentions, rules, values, distinctive power positions and aspirations. The chapters by Cantat, Karolak, and Sahraoui have offered particularly refined accounts of citizens' encounters as subjects and agents of various immigration and integration measures. It is noteworthy that the majority of the authors have examined those subjects of policy measures who are marginalised, placed at the bottom of the societal hierarchy and face precarious working and living conditions. The conceptual and empirical links to approaches in the broader literature which articulate the notion of common marginalisation should be acknowledged here. These approaches investigate the economic, political and ideological forces that generate surplus populations - such as undocumented migrants, refugees, the deportables, precarious night-workers, the Roma and other racialised poor (Rajaram 2015).

Notable exceptions to marginality have been captured by Karolak in the lives of 'successful' Polish return labour migrants and by Desille in those of the new Russian immigrants in Israel. These migrants are posited as norm groups whose aspirations and assets contribute to social integration. The portrayal of the resourceful and welcome migrants is an important stepping stone to expanding the complexity of integration research. The experiences presented in the volume endorse the analytical attention stressed by Glick Schiller and Çağlar (2011, p. 12) about migrants' multiple pathways, diversified engagements in transnational connections and participation in generating alternative social visions. Karolak and Sahraoui have also revealed in their respective chapters, however, that not all agential positions among mobile people and concerned citizens end up in empowerment and capacities to resist disintegration.

The reader will notice that the authors of the volume have not been captured by the epistemological cage of the nation-state. The nation-state 'burden' is carried through the book in a reflexive manner. The investigations explicitly target configurations that frequently take the most powerful shape and claim authority within nation-state structures. Instead of seeing through state structures, the authors have advocated for seeing within and across state structures through observing multiple actors' perspectives - including people on the move, second- and third-generation migrants, sub-national/local service providers, official policy-makers, opinionmakers and citizens of various identity constructions. As several streams in migration research, the volume considers sub-national and local policy measures, economies and civil society actions and their supporting frames through their contributions to integration politics and policies, and their frequently enacted defi- 
ance of higher-level policy paradigms. Space has been left to further investigate the conditions under which governance and bottom-up citizens' actions not only tolerate but $d o$ support solidarity and equality-driven interactions in local settings.

The volume's sharpened attention to what is imagined, referred to and organised within the nation-state context creates noteworthy intellectual linkages with other scholarly efforts to capture political and social changes that may debase the static, demobilising or self-enacting energies of nation-state structures. In the contemporary world of nation-states, nationhood is the default boundary of social membership (Banting and Kymlicka 2015), yet various utterances, reflections and acts regarding collective belongings do question the principle of bounded nation-states protected by membership privileges. It would be an enticing opportunity for the authors to investigate whether the dominant, dissecting or resistant framing and practices described in this volume encourage any alternative articulations of belonging and structures of integration by enhancing rather than restricting equal citizenship. It is also with the aim of furthering scholarly efforts to explore how collisions and collusions of global capitalism and nation-state practices co-produce regimes with their differential relations to boundaries and bounded belongings. An inspiring track in the literature is composed of scholarly contemplations at the intersections of migration and labour studies, exemplified in a recent collection of studies to which several authors of the current volume have also contributed (Fedyuk and Stewart 2018). Governed localities with distinctive identities and representations, like socially diverse cities, are at the centre of another stream in the literature which also offers composite observations on these collisions and collusions (Çağlar and Glick Schiller 2018).

The final set of reflections concerns the difference between scholarly and policy reasoning which intrigues several authors in the volume. They harness open and non-normative analytical positions to identify the main dimensions, levels and forces in politics of (dis)integration. With such an approach, they intend, in the first place, to distance themselves from the regular reasoning of integration policies in which a legitimate distinction is made between migrants and non-migrants, and duties and entitlements, and in which it is usually those born outside the borders, who have to conform to the norms of the host society. The non-normative principle is strictly observed even against some progressive moments and trends in post WW II history when the relations between moving and 'hosting' social groups has been envisioned as largely mutual and the mainstream societal norms, positions, and practices have also been doomed to change. With due respect to the scholarly drive to position research as non-normative, the notion of (dis)integration still connects the horizons and the vocabularies of policy-making and scholarly thinking. The authors in this volume have made prominent efforts to engage with the field of "critical policy studies' without explicitly claiming it, in which the production of power positions and the articulation of policy paradigms and measures are discussed in a joint analytical framework (Clarke et al. 2015). Policy frames, categories and regulatory acts are always products of contentious relations of power holders, the subjects and commentators of policies. Resonating with this approach, scholars in this volume seem to be ready and well prepared to conduct inquiries on the multiplicity and heterogeneity of the ways in which policies are done and policy effects are demonstrated and interpreted. 
Non-normative positions regarding policy-making, however, cannot be fully detached from normative assumptions on wider political and moral grounds. The chapters in this volume do not refer directly to any elaborate theories of justice but their reasoning is unambiguously normative. The authors' choice to dwell on the powerless, the neglected and the undeserving, their critical attitude to preventive and restrictive power structures - in particular for maintaining borders and limiting welfare provisions - enacts and endorses positions on social injustices. They address humanity, solidarity and the extension of citizenship rights when formulating critical insights into (dis)integration policies and practices. The researchers in this volume have been ready to tease out the embodied controversies, negligence and cracks in the theorems and governance infrastructure of (neo)liberal political and social systems, increasing disparities and selectivity in allocating resources and opportunities, even if neoliberalism is not used as an all-encompassing explanatory scheme. All these properties of the intellectual space generated in this volume are unquestionably normative in a broader political and ethical sense. The tensions and consequences of critically reading integration policy formations, as critical policy studies suggest, and commenting on the normative justice arguments within those policy formations, often with the same conceptual repertoire, could be the subject to further scholarly cooperation within the authors' immediate or wider circle.

The young academics involved in this volume seem to stand between two diverging viewpoints regarding the wider questions of the nature and potential of migration and integration research. One is imbued with a belief that integration policies are able, at least in principle, to produce public good. A credible voice of this sort is articulated by those who seek reforms or paradigmatic changes in European integration policies, which are both possible and desirable, and use critical social research to assess progress towards these changes. A fresh volume edited by Scholten and Van Breugel (2018) argues that a new policy paradigm is in the making, inspired by an understanding that migrant groups are becoming heterogeneous, often cultivate multiple identities and incorporate generational difference within ethnic belonging. Therefore, mainstreaming ideas which link the specificities of a particular social group to structures and institutions of society as a whole are potentially more prepared to respond to the heterogeneity of migrant groups (ibid.). The assessment of mainstreaming experiments offers a less than moderately optimistic account, yet the trust in public policies to deliver virtuous social outcomes remains tangible. The other account on policy-making describes integration interventions as regularising and concealing exclusions. Policy and law-enforcement practices produce illegality and irregularity among migrants, which inclusion policies then strive to mitigate. The tandem process results in the collapse of the dichotomy of exclusion and inclusion and fosters disintegration through selective and limited integration. The most salient form of this lapse - border control - reveals the 'obscenity of power'. Public policy in this theorem in fact produces minority citizens and naturalises a chasm of social difference (De Genova 2013). The authors of this volume possess a great deal of intellectual autonomy and have a substantial body of own research that protect them from quickly choosing between these opposing views. They are on their way to positioning themselves in the wider spectrum of theories concerning the interfaces between critical policy thinking and critical scholarship. And it will be abso- 
lutely credible if they still end up with allying with one of these intellectual positions by continued efforts to explore politics of (dis)integration.

To conclude with the most far reaching theoretical puzzle, the notion of migrant integration as a research agenda is contested by several authors due to its inherent assumption that there is a society out there with its reified inside to which the migrants and refugees as outsiders shall be related and positioned (Schinkel 2018). To embrace the notion of integration entails that scholars dock their analytical instruments to the dominant products of political imagination. The most critical move to explore exclusions endorses the underlying patterns of societies' inner and outer spaces, positions, and entitlements in an unwanted way. To imagine what happens when 'migrants' move against the grain of today's 'immigrant integration' discourse, it is important to undo the existing imagination about what happens when people move and settle in another country (ibid. pp. 8-9). I propose that critical scrutiny to the exploitative and separating processes and citizenship practices in the present shall not be weakened or beaten by drives to imagine radically different social conditions and human relations. Social collectives do produce inner and outer worlds and actors, which the vocabulary of inclusion and exclusion, or in this volume, integration and disintegration tries to capture and unpack. Conceptual and framing proposals for critical research are not neutral instruments but may not be the main culprits in generating exploitations and separation between various groups and spaces in society. Critical alertness, however, is essential to the social and political lives of our key concepts as exemplified by the authors of this volume.

\section{References}

Banting, K., \& Kymlicka, W. (2015). The political sources of solidarity in diverse societies (Working Paper RSCAS 2015/73). Florence: European University Institute.

Çağlar, A., \& Glick Schiller, N. (Eds.). (2018). Migrants and city-making: Dispossession, displacement, and urban regeneration. Durham: Duke University Press.

Clarke, J., Bainton, D., Lendvai, N., \& Stubbs, P. (2015). Making policy move. Towards a politics of translation and assemblage. Bristol/Chicago: Policy Press.

Crul, M. (2016). Super-diversity vs assimilation: How complex diversity in majority-minority cities challenges the assumptions of assimilation. Journal of Ethnic and Migration Studies, 42(1), 54-68.

De Genova, N. (2013). Spectacles of migrant 'illegality': The scene of exclusion, the obscene of inclusion. Ethnic and Racial Studies, 36(7), 1180-1198.

Favell, A. (2014). Immigration, integration and mobility. New agendas in migration studies. Colchester: ECPR Press.

Fedyuk, O., \& Stewart, P. (2018). Introduction. In O. Fedyuk \& P. Stewart (Eds.), Inclusion and exclusion in Europe (pp. 1-14). Colchester: ECPR Press.

Garcés-Mascareñas, B., \& Penninx, R. (2016). The concept of integration as an analytical tool and as a policy concept. In B. Garcés-Mascareñas \& R. Penninx (Eds.), Integration processes and policies in Europe (pp. 11-30). Cham: Springer Open.

Glick Schiller, N., \& Çağlar, A. (Eds.). (2011). Locating migration. Rescaling cities and migrants. Ithaca/London: Cornell University Press.

Hamann, U., \& Yurdakul, G. (2018). The transformative forces of migration: Refugees and the re-configuration of migration societies. Inclusion, 6(1), 110-114. 
Lafleur, J.-M., \& Mescoli, E. (2018). Creating undocumented EU migrants through welfare: A conceptualization of undeserving and precarious citizenship. Sociology, 52(3), 480-496.

MacQuarie, J-C. (2018). Invisible migrants: Glocturnal cities' 'other workers' in the post-circadian capitalist era. PhD thesis, Central European University, Budapest. Retrieved April 1, 2019, from https://bit.ly/2FCMkFX

Mezzadra, S., \& Neilson, B. (2013). Border as method. Durham: Duke University Press.

Mügge, L., \& van der Haar, M. (2016). Who is an immigrant and who requires integration? Categorizing in European politics. In B. Garcés-Mascareñas \& R. Penninx (Eds.), Integration processes and policies in Europe (pp. 77-90). Cham: Springer Open.

O'Cinneide, C. (2013). Completing the picture: The complex relationship between European antidiscrimination law and 'social Europe. In N. Countoris \& M. Freedland (Eds.), Resocialising Europe in a time of crisis (pp. 119-137). Cambridge: Cambridge University Press.

Rajaram, P. K. (2015). Common marginalisation: Neoliberalism, undocumented migrants and other surplus populations. Migration, Mobility \& Displacement, 1(1), 67-80.

Rass, C., \& Wolff, F. (eds) (2018). What is in a migration regime? Genealogical approach and methodological proposal. In A. Pott, C. Rass \& F. Wolff (Eds.), Was ist ein Migrationsregime? What is a migration regime? (pp. 19-64). Wiesbaden: Springer.

Rozakou, K. (2017). Nonrecording the 'European refugee crisis' in Greece. Focaal: Journal of Global and Historical Anthropology, 77(1), 36-49.

Sajjad, T. (2018). What's in a name? 'Refugees', 'migrants' and the politics of labelling. Race \& Class, 60(2), 40-62.

Schinkel, W. (2018). Against 'immigrant integration': For an end to neocolonial knowledge production. Comparative Migration Studies, 6(31), 2-17.

Scholten, P., \& Van Breugel, I. (2018). Introduction. In P. Scholten \& I. Van Breugel (Eds.), Mainstreaming integration governance: New trends in migrant integration policies in Europe (pp. 3-22). Cham: Palgrave Macmillan.

Shaw, J. (2005). Mainstreaming equality and diversity in European Union law and policy. Current Legal Problems, 58(1), 255-312.

Varsanyi, M. (2008). Rescaling the 'alien'. Rescaling personhood: Neoliberalism, immigration, and the state. Annals of Association of American Geographers, 98(4), 877-896.

Yanow, D., Van der Haar, M., \& Völke, K. (2016). Troubled taxonomies and the calculating state: 'Everyday' categorizing and race-ethnicity'. The Netherland case. Journal of Race, Ethnicity, and Politics, 1(2), 187-226.

Yildız, C., \& De Genova, N. (2017). Un/free mobility: Roma migrants in the European Union. Social Identities. https://doi.org/10.1080/13504630.2017.1335819.

Open Access This chapter is licensed under the terms of the Creative Commons Attribution 4.0 International License (http://creativecommons.org/licenses/by/4.0/), which permits use, sharing, adaptation, distribution and reproduction in any medium or format, as long as you give appropriate credit to the original author(s) and the source, provide a link to the Creative Commons licence and indicate if changes were made.

The images or other third party material in this chapter are included in the chapter's Creative Commons licence, unless indicated otherwise in a credit line to the material. If material is not included in the chapter's Creative Commons licence and your intended use is not permitted by statutory regulation or exceeds the permitted use, you will need to obtain permission directly from the copyright holder.

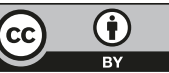

